\title{
II. Jomrualliteratmer.
}

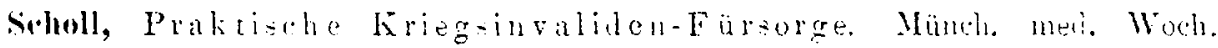
$1916.2-3$.

Vert. schihlert in lesens- unt woeh meh beachtenswerter Weize lio Eurde-

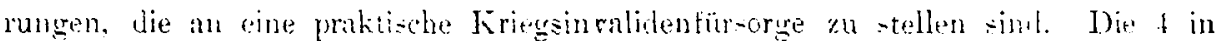
Betracht kommenden Faktoren: aizdliche Masnahmen, Berufsheratung, Berufs-

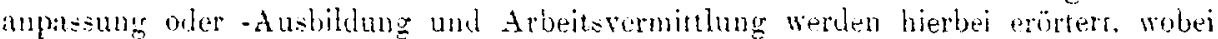
Verfasser die in Buven und insbeonlere in Oberhavern München: cretrofenen Masuahmen anführ, dies im wesentlichen nit dea babntrechemlen spitzy seben Einrichtnugon äbereinstimmen.

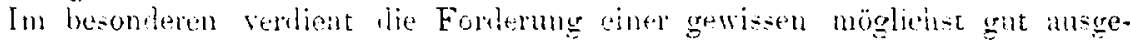
- Latteten Zentralitelle, weitehin das Verlangen, dass die Invaliden schon währond

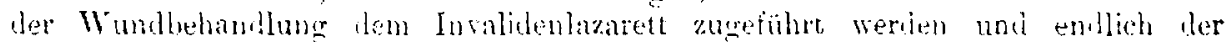

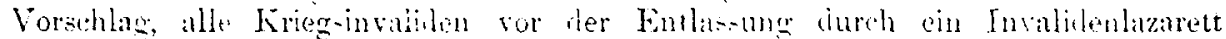

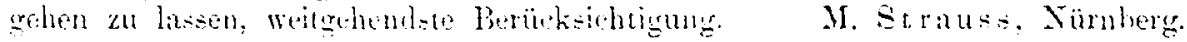

Muskat, Berlin: Die orthopadi-che Sarhbehandlung von Kriegsverletzungen und tie militärocher-eit- hierfir wetroffonen II a $=$ : $n$ a h m men.

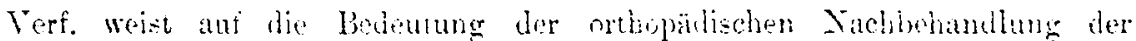

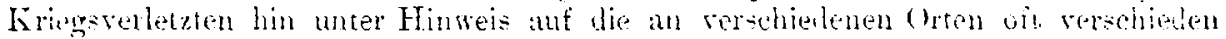

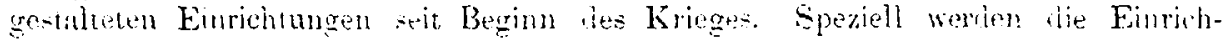

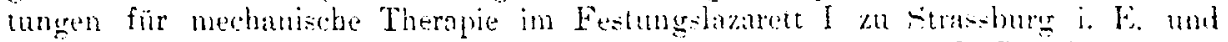
die hier gremachten Erfahrmengen erontert.

J. Rituinger.

Joh. G. Chrysospathes, then: C̈ber eint supinations-lixentions-

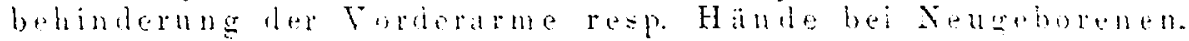

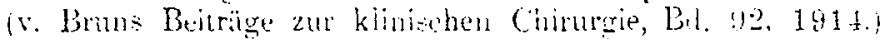

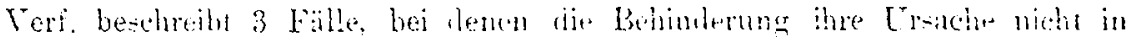

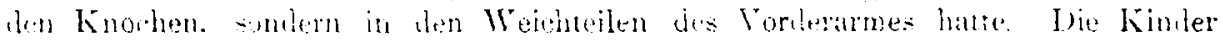

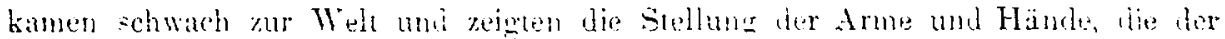

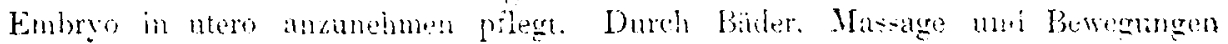

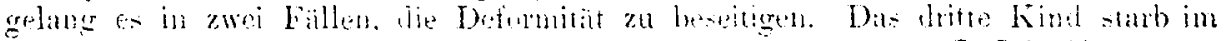
7. Teben-monal an Entibritulag.

J. Rielinger.

\section{[1]. Misteilumentl.}

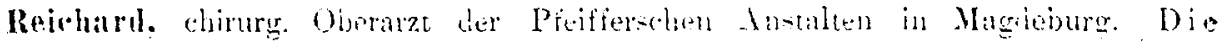

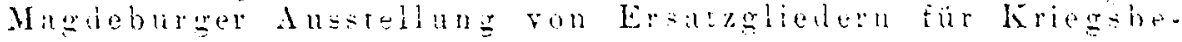
schäligte.

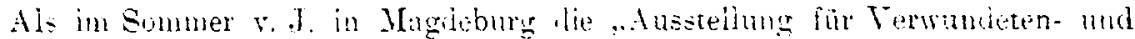
Krankentursonge in Kriege sattaml, whe in ten Kreteen der hiesigen hrippel-

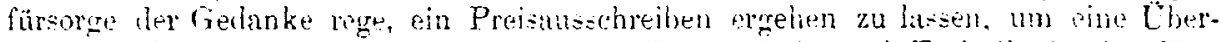
sicht darüber gewinnen zu können. was Wisensehaft und Terhnik in der Herstelhumg ron Prothemen uni Beholfoipnaraten heure zu leisten vermïgen. und

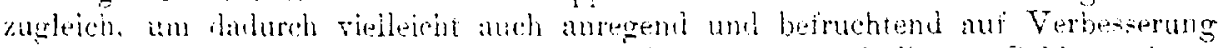

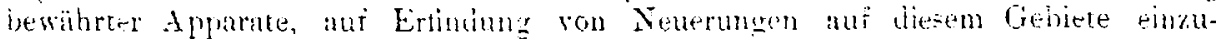

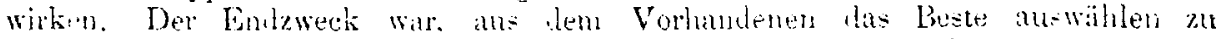

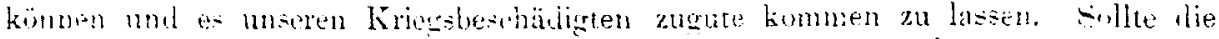

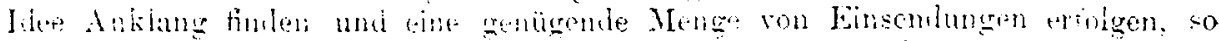

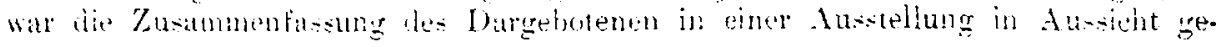

